\title{
On Semiotics Perspectives of Computational Thinking: Unravelling the "Pamphlet" Approach, a Case Study
}

\author{
Vladimiras Dolgopolovas *(1) and Valentina Dagiene (1)
}

check for updates

Citation: Dolgopolovas, V.; Dagiene, V. On Semiotics Perspectives of Computational Thinking: Unravelling the "Pamphlet" Approach, a Case Study. Sustainability 2022, 14, 1956. https:// doi.org/10.3390/su14041956

Academic Editors: Margarita Pino-Juste, José Antonio Marín-Marín, Antonio José Moreno Guerrero and Jesús López Belmonte

Received: 16 December 2021

Accepted: 7 February 2022

Published: 9 February 2022

Publisher's Note: MDPI stays neutral with regard to jurisdictional claims in published maps and institutional affiliations.

Copyright: (C) 2022 by the authors. Licensee MDPI, Basel, Switzerland. This article is an open access article distributed under the terms and conditions of the Creative Commons Attribution (CC BY) license (https:// creativecommons.org/licenses/by/ $4.0 /)$.

\author{
Institute of Data Science and Digital Technologies, Vilnius University, Akademijos Str. 4, \\ LT-08412 Vilnius, Lithuania; valentina.dagiene@mif.vu.lt \\ * Correspondence: vladimiras.dolgopolovas@mif.vu.lt
}

Abstract: Computational thinking (CT) is in the midst of an ongoing debate about its scope and definitions. There is a trend away from a "traditional" computer science-inspired agenda towards a focus on universal competences for today's labor market. However-and this is the motivation behind the research-the shift described is just an unconscious attempt to reveal the immanent nature of CT as an evolving semiotic phenomenon. The aim of this study is to explore directions and perspectives for the further development of CT and related methodological design approaches. As a research strategy, this article utilizes a case study on the presented set of resources dedicated to CT early education and reveals it in terms of multimodal discourse analysis. As a result, a landscape of future CT trends is presented, uncovering CT from a multimodal semiotic perspective. This article discusses various issues related to $\mathrm{CT}$ and its multimodal semiotics nature, perspectives on the design of CT-related resources and additional educational issues such as the perspectives on instructional approaches for CT teaching. We conclude that $\mathrm{CT}$ as a social phenomenon is in the process of an evolutionary transformation of its constitutive structure in the direction of further revealing its agentive semiotic nature.

Keywords: Computational thinking; educational policy; early education; multimodal semiotics; futures studies; sustainability issues

\section{Introduction}

Computational thinking $(\mathrm{CT})$ is a transdisciplinary phenomenon having a great impact on the contemporary educational agenda. Starting with the claim of an improved educational methodology, it has evolved into a system of theoretical foundations and practical prerequisites for a holistic approach to educational transformations. These transformations took place within a further refinement of the direction of educational methodologies aimed at personal development issues from the moment of birth and moving towards the identification of a spectrum of activities for the acquisition of professional skills and their corresponding advanced competences. In addition, this system of transformations aims at a socially oriented agenda. All of this allows for the outlining of the modern understanding of the CT phenomenon as a holistic socio-methodological concept, combining communicative and methodological approaches.

CT methodological approaches, as historically established, focus primarily on the development of skills and competences. We can talk about an inward direction (directly towards the learner) of the development of his or her cognitive abilities and digital and other competences. Communicative approaches, on the other hand, are directed outwards to the surrounding social environment in order to guide and sustain the social transformation associated with an educational process. Based on this, the modern CT landscape brings together educational approaches, methodologies and communities grounded in different understandings and implementations of CT and its agenda. Furthermore, the broader introduction of CT into the educational landscape has enabled the development and 
promotion of a new understanding of already existing educational paradigms such as family literacy [1,2], science, technology, engineering and mathematics (STEM) [3-5] or contest-based learning [6] and claims for supporting the emergence of new educational approaches and methodologies such as the Maker movement [7] and the "public science" [8] agenda. However, derived from its technical background, we observe that CT still retains its "traditional" developmental tendency $[9,10]$, leaving its role in and impact on cultural and related societal transformations underestimated.

In general, CT remains closely tied to its technical past, which leads to the persistence of the "traditional" understanding of CT as closely related to computer science or coding education with variations of this topic [11]. However, its role in cultural and societal transformations remains largely underestimated. The above considerations determine the motivation for this research-to explore the possibilities for the further understanding of CT-mediated societal transformations. Our interest, beyond the theoretical aspects, lies in the practical dimension of designing CT-related heterogeneous entities, such as, for example, a set of solutions for early development and education. We understand the practical dimension, as mentioned above, as part of a holistic methodological, cultural and social agenda that deals with a series of complex educational, cognitive, cultural, societal and technical problems, that is transformed into a heterogeneous network that combines human and non-human and material and non-material entities into one integrity. The aim of this study is to explore directions and perspectives for the further development of the $\mathrm{CT}$ phenomenon related to approaches to its methodological and communicative design.

Our research strategy is a mixed-methods study that includes an analytical study and experimental research in the form of a case study. The main characteristics of a case are [12]: (a) it has to be a self-sufficient entity; and (b) it has to have clear boundaries. The case we examine is related to a public educational institution, a public libraries association, and is limited to the area of early development and education. This enables the following research questions to be formulated: (R1) How is the CT phenomenon, represented by the storyline of early literacy and early childhood education, conceptualized through the medium of a public institution, namely the association of public libraries? (R2) What are the main directions of the development of the CT phenomenon, considering it as a multimodal semiotic resource?

With regard to environmental and sustainability issues, CT and its related educational activities make significant contributions to the topic of social, economic and environmental sustainability. For example, the introduction of sustainability issues expands STEM-related educational programs through a series of relevant and engaging learning activities $[13,14]$. The Maker movement, enabled and supported by digitalization and CT, is actually based on technological advancements such as "long-tail" marketing [15] and redistributed manufacturing methods [16]. This introduces a number of opportunities, leading to a new social environment of responsible citizens, combined with increased flexibility with respect to the environmental impact of production and the circular economy [17,18]. At the same time, this enhances environmental resilience to future trends, such as irreversible climate change and the increasing globalization of supply chains [16]. As a consequence, CT can be seen as a precondition for a professional competence on sustainability [19], connecting the Maker movement, CT and STEM to professional and educational environmental issues.

The structure of this paper is as follows. In the next section we describe the concepts that we believe are most relevant to CT-driven societal transformations, namely the concept of a complex socio-technical system, the meaning of "societal concept" and the concept of a heterogeneous network in its dynamics and transformations. This provides the theoretical framework for the study, its methodological part and its content. What follows is a comprehensive theoretical introduction to the methods used. In general, we consider the topic and the approach implemented in this study to be innovative. This study is based on a combination of theoretical research and practical "experiments" in the form of an insight into one practical example of a CT artifact related to early development and education. In this regard, we are looking for methodological invariants that can be seen as a kind of 
"methodological driver" of the emerging CT reconstruction. We continue with the section on the methods used for this study.

The next part of the paper presents a study of a sample CT resource. It focuses on a comprehensive examination of one illustrative case that provides room for insight based on the theoretical and methodological considerations developed. This part begins with a descriptive section on the results, focusing on the case description and corresponding analytical insight. This is followed by a detailed discussion of the prospects of the phenomenon in terms of its conceptual understanding, which presents the developmental trends in the form of the CT phenomenon development matrix. We conclude with a section on the prospects for $\mathrm{CT}$, which is considered as an emerging semiotic phenomenon.

\section{Background}

\subsection{Moving beyond the Digital Agenda}

The theoretical background of this study integrates a number of well-grounded methods to develop a holistic approach to the study of such a complex phenomenon as CT. These relate to (1) semiotics and semiosis, (2) design theory, which draws on the considerations of actor-network theory (ANT) and (3) futures studies. As can be seen from the previous section, in formulating a new agenda for $\mathrm{CT}$, we draw on an extensive range of meanings, such as those of system, concept, societal transformations and heterogeneous networks. However, the internal structure, the definition of what CT is (with which all research CT topics usually begin) is left out. The reasons for this are that (1) we focus our research efforts on the phenomenon of $\mathrm{CT}$; as such, we consider the sociogenic features it mediates most important to study, and (2) we seek to study the phenomenon in its dynamics, assuming that $\mathrm{CT}$ is in the process of emerging transformations, thus leaving its internal structure (its models or definitions, as understood in its "traditional" meaning) out of the picture at this stage of the research.

We first explore the possibility of considering the phenomenon of $\mathrm{CT}$ from a sociotechnical perspective. Can one consider $\mathrm{CT}$ as an example of a complex sociotechnical system [20] and what are the principles of designing of its entities? Firstly, CT includes cognitive aspects, as it aims at the cognitive development of learners, so cognitive and related human problems are important to consider. Further, it is interdisciplinary, as it requires the incorporation of social, political and economic issues into its framework. This is particularly evident when observing CT-mediated institutions such as STEM and the Maker Movement $[5,21,22]$. Finally, computing, programming and related technical aspects are important for CT [23]. Computational approaches have traditionally been based on the notion of computing, computer science and related issues of predominantly technical origin. In order to design such a complex social domain, it is necessary to "distinguish important features that contribute to a domain's overall complexity" [24] and to apply this to CT. However, the difficulty with this "straightforward" approach is that CT as a phenomenon encompasses methodological, social, technical and political planes. Moreover, it combines tangible and intangible and human and non-human entities into a single whole, which requires more comprehensive approaches to its design.

Sociotechnical design approaches, on the other hand, claim a pragmatic nature and transformative systemic change [24,25], which is a major challenge for CT designers. The solution is to move from systemic design approaches to a vision of "incremental change" [24], moving beyond an artifact-centric design philosophy to design the "landscape" of the kind of "socioecological" system that the CT phenomenon represents, while paying attention to social, cultural and political issues as well as assessing the complex social interdependencies [24] that CT mediates.

The meaning of "concept" brings us to a semiotic understanding of CT. Generally speaking, employing the pragmatist stance of semiotics [26], CT is seen as a "signifying" phenomenon representing a complex, multimodal "object", namely the set of multimodal resources to which CT refers. The "interpreting agent" is human (student, educator, politi- 
cian, education stakeholder, etc.) or non-human (software, methodology, digital profile, network, etc.), which makes the interpretive process complex and interesting to study.

When developing the $\mathrm{CT}$ design framework, one can consider $\mathrm{CT}$ as a representative of the family of "cognitive artefacts" [27], a kind of mental enhancer, considering its design principles [28]. However, CT has a number of specific features of its own, such as "intangibility", it is more of a concept than an "entity" and it is a "mediating" artifact (at least in our interpretation), so the design principles associated with cognitive artifacts need to be further adapted. These ideas move us towards an understanding of design practices based on ANT perspectives [29] as applied to CT. This perspective allows us to position $\mathrm{CT}$ as an "assemblage", answering further questions about its design practices. In general, two design paradigms can be mentioned. The first, positivist, is based on the work of Simon [30], which argues for systematic approaches to design, and the other, pragmatic, is constructivist, which leads to a kind of "bricolage" approach to design [31]. The latter, a constructionist [32] vision, gives us an idea of how to consider the aspects of designing CT: we should design it from "materials" and "blanks" that are available and "at hand regardless of the digital/non-digital aware of critical pedagogy, not to be seduced by the technological determinist discourse and to increase agency for all involved" [31].

The meaning of "network" further refers to a number of considerations related to ANT and its design applications [29,31]. In line with all this, the following program could be implemented in the design of a CT:

1. What is this specific "script" inscribed into CT? Since we deny the claim of universality, such a process of "scripting" depends on discourse and should develop, as is usual for pragmatist activity, through a kind of anthropological insight, understood as broadening the perspectives of "applied ethnography" [33] and as a penetration into a field of artificiality.

2. What is the affordance of CT (on the meaning and discussion of the term "affordances" as applied to semiotics and education see, for example, [34])? This question is addressed from an extended socio-cultural perspective. Such extension aims: (a) to highlight "perceptions" (Norman, 1999 as cited in [29]) in relation to educational methodology, namely, how perceived affordances per se are relevant to "everyday" pedagogical practice occurring in the CT landscape; (b) to further relate to a revision of the "ecological" approach to visual perception [35], conditioning affordances on culturally dependent functional significance (Helf, 1989 as cited in [29]). This is an important shift, as it provides us with a link from the cultural to the social, bringing us to the questions of post-digital values and cultural impact on societal attitudes toward technology and digitalization [36]; and (c) at the same time, this extended view of affordances links us to the meaning of (ecological) semiotics [37], as will be shown later. Namely, understanding the semiotic features of CT leads us to the conceptual understanding of the prospects of the CT phenomenon. Where is the physical in CT? Could "ecological perception" "assist" to solve the problem of signifier-signified dualism for such an "abstract" entity as CT? In practice, this means instead of focusing on "hidden" meanings and searching for "deep" concepts, one should focus on a "pragmatic approach to semantics" [37] and on highlighting the practical affordances that CT offers the interpretant in a broader sense. It is important to note that this "perception of affordances" is culturally dependent, therefore "refining" this related cultural discourse is another challenge for "proper" CT design.

3. What is the mediating role of CT? According to classical ANT definitions, "a mediator can transform, translate, distort and modify meaning" (Latour 2005 as cited in [29]). In relation to semiotic focus, we could be practically interested in the transformational and transductive potential of $\mathrm{CT}$, seen as a multimodal semiotic resource [38] and taking into account its contingent behavior.

4. How are the sociogenic features of CT imposed? What is delegated and what is prescribed back? Here we look at $\mathrm{CT}$ as a non-human agent or mediator, unravelling its inherent roles and impacts on network actants. 
Further emphasizing the semiotic nature of $\mathrm{CT}$ as related to educational applications, it is important to highlight the role of "epistemic controversy" [39] as a kind of a "driver" to develop its inherent contingency. Namely, "semiotic learning is different from computational learning" [34], where the former is positioned as "phenomenological" as opposed to the "mentalistic" grounding of the latter [34]. This leads to a broader discussion of a "need for an embodied account of meaning" [34] (on the notion of embodiment, see, for example, [40]). Looking ahead, this highlights a current state of affairs in approaches to CT instructional design, which emphasize a "mentalistic" or "computational" type of learning, while "phenomenological" or "ecological" approaches remain underestimated.

As an example, the meaning of "semiotic scaffolding" can be further discussed. New possibilities emerge and, as a consequence, new affordances (in a semiotic sense) are "discovered" through "evolving modes of semiotic engagement" [34] and through the scaffolding of previous experience. Scaffolded learning thus overcomes its inherent incompatibilities by providing directions and introducing a kind of constraint. Here we are talking about a semiotic focus of instructional design, revealing affordances in the direction of, for example, semiotics "mappings" as uncovering the transformative and transductive potential of CT. More generally, this leads to a paradigm shift in goals and approaches to CT design from a utilitarian-pragmatist focus on means and intentions to a pragmatist-teleological focus based on Kant's notion of empirical cognition [41] and its implications for the development of biosemiotics [42].

\subsection{Methodological Considerations}

The study itself draws on the following research methodologies: multimodal discourse analysis (MMDA) and ANT perspectives of design and futures studies. (A) MMDA is grounded in social semiotics [38], thus maintaining the claim of contingency and providing a "spot" for a kind of "fieldwork". CT is a complex phenomenon that integrates human and non-human entities into one constantly evolving network. Multimodal analysis enables this complexity to be emphasized, with equal attention paid to all details of its constitution. (B) ANT perspectives on design $[29,43]$ provide a holistic vision of design practice, revealing the mediating role of $\mathrm{CT}$ in the educational and related environments in which it is embedded. At the same time, ANT strengthens the conceptual understanding of CT and its role in the current and future transformations of the highly heterogeneous educational network in which it is involved. (C) Futures studies perspectives [44] reveal CT in its development dynamics and highlight $\mathrm{CT}$ trends and perspectives. Understanding such perspectives enables $\mathrm{CT}$ teaching methods and principles of instructional design to be current and relevant in terms of understanding what $\mathrm{CT}$ is and what the contours of its emerging constitution are.

The methodological approach of our research is to uncover the "non-traditional" aspects of $\mathrm{CT}$, such as the prospects of implementing an ANT-empowered design and utilizing MMDA perspectives for discourse analysis. At the same time, following the aim of our study, we consider aspects related to future studies as equally important. To be practical, we seek invariants of the multi-paradigmatic approach that we declare-namely semiotics—as the key feature of the approaches presented.

What is semiotics for ANT empowered design? Generally speaking, the semiotic nature of CT is uncovered in its conceptual-mediating role as a semiotic actor (actant) in the network it develops and mediates. Concepts such as hidden meanings, agentive features, scripts, prescription, delegation, mediation, semiotic affordances [29] and non-human and cognitive artifacts $[28,33]$ are key to uncovering the inherent semiotics features of CT. It is the uncovering of these semiotic perspectives that provides us with a toolset for the new approaches to the "phenomenological" design of CT that we seek.

What is semiotics for MMDA? The MMDA semiotics agenda imposes social transformations trough the agentive roles of sign makers, while at the same time implicitly claiming to be a "flat" ontology [45], which is in line with ANT perspectives. Grounded in social semiotics [46], which "sees systems of meaning as fluid, contingent and changing in 
relation to context, history and culture", MMDA seeks "to make conceptual connections between motivated signs, sign makers, interest and the choice of modal and semiotic resources used in a text" [38]. Starting with an analytical study of the artifact, its constitutive structure, genre and overall context, one moves on to an analysis of the use of modalities (considering this as an agentive means), modally related semiotic resources and modal affordances. Issues of intermodal relations, modal dominance and coherence of multimodal constitutive structure are important here. One of the most important points is design as relating to the "micro" level [38]. Therefore, from the design perspective, MMDA and ANT complement each other, as MMDA focuses on the "internal" and ANT on the "external" aspects of design.

What is semiotics for futures studies? Considering dialectics as a kind of "framing" approach, we can be involved in the "dynamic interactions of opposing concepts/systems through thesis, antithesis and synthesis" [47]. Such (epistemic) controversy of (semiotic) concepts (see [39] for science and technology studies-driven discussion on epistemic controversies or [48] for a driving role of metaphoric "clashes" in modern technology development) will lead to a "reconstitution" of the CT phenomenon, pushing back from a dialectic of thesis-antithesis, such as "traditional" and "new" (Denning, 2017 as cited in [49]), and as a result, by moving through today's chaos and search for identity and passing through "the zone of indeterminacy" [47], a newly "synthesized" CT entity will emerge. There are several key aspects to be highlighted in this respect. First is the notion of hierarchy [50]. The "battle" of the previously mentioned dialectical contradictions is actually not a "battle", it is a kind of "dispute" based on a (temporal) hierarchy, which should be uncovered through a comprehensive study of the phenomenon itself. A new essence will (possibly) emerge as a result of hierarchical shifts, forming a new hierarchical structure. The next is "perception and interpretation" [37], arguing that the process of interpretation is a matter of the individual. Thus the "struggle" for conceptual universals or the claim for a "prescriptive" role of science is not the focus. The focus should be done on "opening up" affordances and providing a scaffolding for the "learning of associations" (Gibbson, 1966 as cited in [37]).

We make a claim to contingency (on the meaning and discussion of the term "contingency" as applied to philosophy, futures studies, social sciences and semiotics, see, for example, [51-54]). In the context of this study, the meaning of "contingent" refers to an understanding of social phenomena as "fluid, contingent and changing in relation to context, history and culture" [38]. This is an important statement, as without true contingency, there is no possibility of development, as it is contingency that provides unpredictable possibilities to be discovered. Discovering these possibilities is a key path for the designer, as any aspiring aims to illuminate the future by embedding such possibilities into the form and structure of the designed artifact. That is the task of the futures studies-to assess consequences by identifying alternatives and investigating "events, emerging trends, images and actions" [44]. We will target that research program, concentrating on the images and emerging trends that need to be addressed.

\section{Materials \& Methods}

The research is based on a case study devoted to a multimodal analysis of early child development and education narratives. As narratives, we consider non-academic content such as publicly available web resources. Discourse analysis, based on a set of methodologies, provides an opportunity to identify the inner essence of the CT phenomenon. Generally speaking, the semantic component of the concept of discourse in relation to the field of education within the framework of its definitions and academic understanding is quite vague [55]. This helps to immerse researchers in exploring ontological or epistemological issues [55] and, on the other hand, expands the potential of futures studies through such "assets" as "indeterminacies, contingencies and difference[s]" [43].

The perspectives of social semiotics are methodologically based on the following questions [37]: Who speaks, to whom, when, with what purposes and in what way? 
What are the inherent meanings? What is the impact on the individual and the society? What are the interests of the text (resource) maker? What are the means and principles for establishing cohesion and coherence in the community? What is the claim for social changes? What is the genre and its relation to other genres? What are the relations of power in social interactions?

Multimodal analysis enables us to study the whole through "micro-observations of modal features" and "placing an emphasis on social contexts and resources of meaning making" [38], generating questions about the artifacts under study [38]: How and what was it created for? How does it relate to connected discourses? Who is the imaginary audience/reader? What is the intended use of this artifact? What does this artifact communicate about the "lifeworld" of the imaginary reader? It is important to stress that a fundamental "premise of multimodal approaches is a concern with the cultural and social resources for making meaning rather than with the senses" [38].

Futures studies are primarily concerned with analytical reflection on a range of precisely contingent alternatives and possibilities for development. The challenge here is that from the position of the "conventionally minded" scholar, it is difficult to understand the case and discourse of transdisciplinary contingency. Such alternatives then go beyond the already developed disciplinary ontology, expanding the landscape of disciplinary discourse with new semantics and interdisciplinary links. The main contribution of our approach is that we reposition CT from its current understanding as an educational and cognitive development tool to consider $\mathrm{CT}$ as a semiotic resource that mediates sociocultural relations in a power network. To identify trends in the development of a semiotic phenomenon such as CT, a tool in a form of matrix of estimates of future directions and trends in the development of the semiotic phenomenon has been developed (see Figure 1).

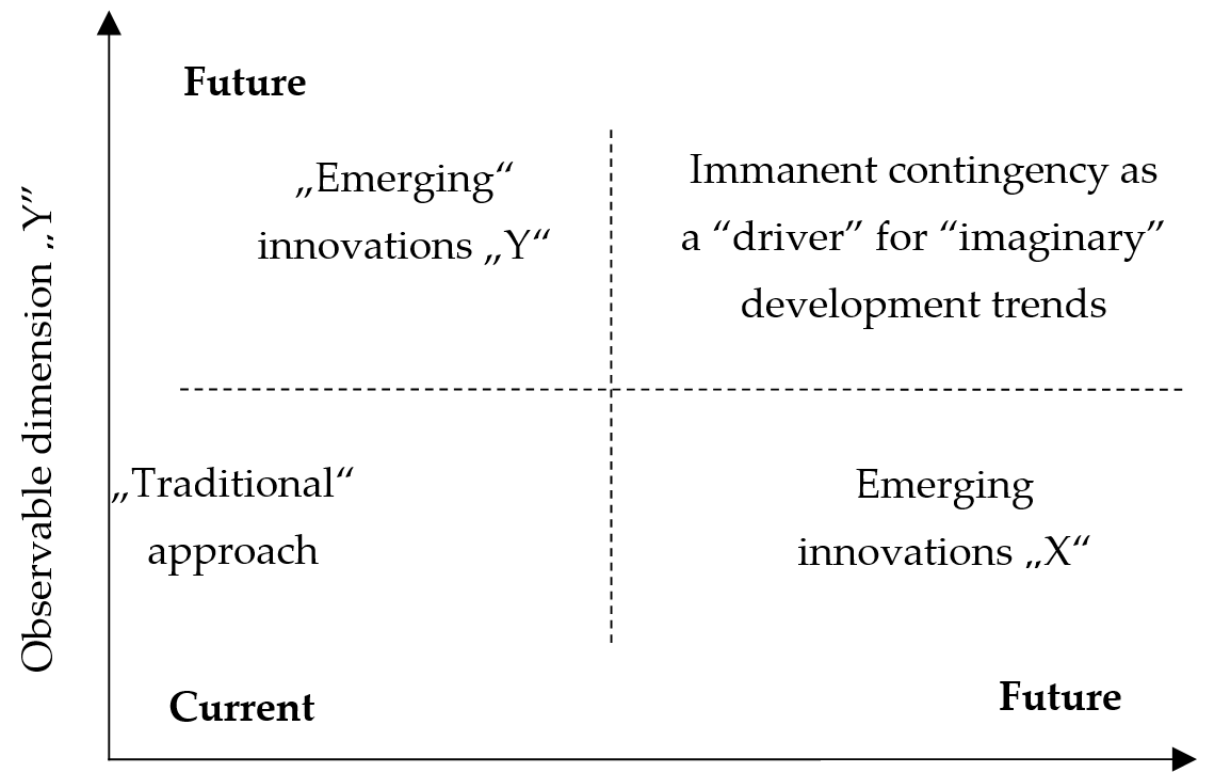

\section{Observable dimension „'X”}

Figure 1. A development trends chart (elaborated by the authors).

We implement a "method-centric" approach [56], combining qualitative methods based on social semiotics and multimodal discourse analysis [38,46,57]. In such a research design, the methodology is isolated from the main study and "appears as the last in the design sequence" [56] (See Table 1). In fact, this approach could be positioned as a kind of "methodological ecliptics", pushing methodology aside at this stage of research and focusing on combining methods in a systematic way. However, it can itself be positioned as an emerging methodology, which accounts for the extensive text on methodology placed in this paper. 
Table 1. Methods: mapping of the semiotic conceptualization of the CT (semiotic triangle matrix) to the matrix of the phenomenon's conceptual trends (elaborated by the authors).

\begin{tabular}{|c|c|c|c|}
\hline & \multicolumn{3}{|c|}{ "Human" Actors and Related Dimension } \\
\hline \multirow{3}{*}{ 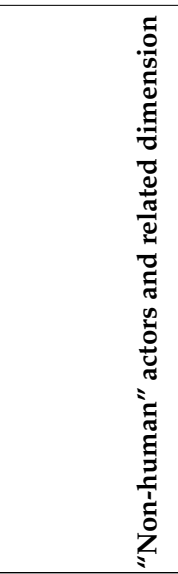 } & & $\begin{array}{c}\text { "Traditional" discourse: } \\
\text { institutional regulations, } \\
\text { educational policy guidelines, } \\
\text { expert "opinions" } \\
\end{array}$ & $\begin{array}{l}\text { "Emerging" discourse: new means for } \\
\text { communication, expression, networking, } \\
\text { mediation, production, marketing }\end{array}$ \\
\hline & $\begin{array}{l}\text { "Traditional" discourse: academic } \\
\text { literature, curriculum, instruction }\end{array}$ & \multirow{2}{*}{$\begin{array}{c}\text { Traditional artefact-oriented } \\
\text { activities, tangible, } \\
\text { understandable environment: } \\
\text { (Non-humans) algorithms, } \\
\text { systems, regulation; (Humans) } \\
\text { experience, confidence, skills } \\
\text { - }- \text { - - - - - - - - } \\
\text { Emerging expression-oriented } \\
\text { attitudes intangible, } \\
\text { social-environment: } \\
\text { (Non-humans) new forms, design } \\
\text { research; (Humans) links, } \\
\text { networking, communication }\end{array}$} & \multirow{2}{*}{$\begin{array}{c}\text { Emerging conceptual-oriented attitudes, } \\
\text { sensitive, socio-cultural environment: } \\
\text { (Non-humans) culture, values, attitudes, } \\
\text { agency; (Humans) conceptual } \\
\text { understanding, interaction, competences } \\
\text { Futures symbiosis, contingent, } \\
\text { transcendence [58], metaphorical [48,59], } \\
\text { virtual [60,61] environment: } \\
\text { (Humans-non-humans) emerging } \\
\text { competences, affordances, perception }\end{array}$} \\
\hline & $\begin{array}{l}\text { "Emerging" discourse: } \\
\text { non-academic writings, } \\
\text { web-resources, manuals, } \\
\text { descriptions of activities }\end{array}$ & & \\
\hline \multicolumn{4}{|c|}{ tures studies methods: "unravelling" conceptual contradictions, driving controversies, clashes } \\
\hline \multirow{2}{*}{\multicolumn{2}{|c|}{$\begin{array}{l}\text { Multimodal discourse analysis methods: messages, forms of } \\
\text { expression, modes, approaches to design }\end{array}$}} & Concept (expression symbolizes) & \multirow{2}{*}{$\begin{array}{l}\text { Actor network theory methods: } \\
\text { tangible/virtual agency, } \\
\text { tangible/virtual mediators }\end{array}$} \\
\hline & & $\begin{array}{l}\text { Semiotics of the CT } \\
\text { phenomenon }\end{array}$ & \\
\hline \multicolumn{2}{|c|}{ Expression (text, other multimodal resources) } & $\begin{array}{l}\text { Social semiotics methods: hidden } \\
\text { meanings, social agency, power }\end{array}$ & Referent (virtual artifact) \\
\hline
\end{tabular}

The set of multimodal resources for the analysis was generated from a linked set of web pages promoted under the CT label and positioned as an integrated set of informational and educational resources developed under the direction of the chosen public institution [62]. The reason why this content was selected is that, from our perspective, it provides an illustrative example of a possibly unconscious attempt to utilize the set of semiotic tools to make CT and its related content "contextualized" by the coherent efforts of the resource makers. The set encompasses a number of extensively linked resources on CT definitions, professional development curricula, family literacy, nonformal education and early development, and includes hypertextual information, video and computer presentations, webinars, brochures, pamphlets, posters, handouts, press releases and other related tools. The web resource also provides a link for authorized access to an online collaborative platform for communities of interests. It also requests feedback om sharing experiences in CT-related activities in the form of examples and descriptions of initiatives.

The general aim of the analysis is to identify hidden meanings and not explicitly stated intentions, as well as the agency behind the resources. The procedure of practical analysis is based on heuristic inquiry $[63,64]$, treating heuristic as a kind of underlying "methodology" for the method-centered approach previously described. In this sense, our approach is explicitly interpretivist, focusing on exploring implicit political motives, searching for embedded political rhetoric and applying a critical stance to the analysis of discourse, which in practice usually means looking for sales, self- and institutional marketing and advertising content. At the same time, our analysis focuses on the search for values, attitudes, agency, actors, hidden political intentions, possible contradictions, clashes and emerging issues, thus assessing trends and possible consequences.

\section{Results: Narrative and Storyline}

\subsection{Storyline: CT from a Librarian's Perspective}

This case study is based on a discourse analysis of a number of open sources which contain a multimodal set of resources on the topic of early development and education. The narrative presented describes the entire CT story related to early literacy and early childhood education. Motivation is an innovative way of supporting the whole child. 
One of the aims is the professional development of library staff and the target group is children's librarians and early childhood educators. The directions of the narratives are: early childhood development and education, the professional development of library staff, a repository for sharing experiences and further information on CT and related topics.

Early childhood development and education struggle with the effects of COVID-19. The proposal is to integrate CT into virtual and non-screen library programs through playbased methods. The definition of CT is twofold: firstly, CT is positioned as an expressive or creative process, and secondly, as a tool for the negotiation of a variety of digital and analog information. The other motivation is that we live in a rapidly changing world; therefore, we need to educate for some universal skills to cope with the ever-evolving uncertainties. Sample virtual programs for CT education are presented.

These programs are systemized by CT and listed thematically and institutionally. Institutions (public libraries) are positioned as providers for early childhood development solutions and practical services. The method is to adapt face-to-face educational programs and transfer them into virtual platforms. There are links to video resources developed (owned) by the participating libraries. Such resources are developed by library staff and have a link to the institution's data in the form of its logo and/or website link. Another type of promoted activity is traditional outdoor activities adapted for CT education. These are positioned as family activities, while at the same time aiming to develop children's creativity and self-confidence. The need for scaffolding for children and families is also pointed out. This is also aimed at families with limited access to digital information.

A more theoretical introduction includes the motivation to develop essential media skills using all forms of communication. It is spoken about on the list of twenty-first century competences for all ages. The role of libraries is in helping families build a foundation for children to engage in more advanced competences when they grow up. A critical aspect is that library staff reassert their dedication to equity by making such competences available to all. The definition of $\mathrm{CT}$ focuses on problem solving and describing the historical development of $\mathrm{CT}$ beyond computer science towards a high order thinking and multidisciplinary mindset. CT is presented in a dynamic way as a growing field that absorbs other forms of thinking, such as creative thinking.

The problem with CT education, is that there is not yet a common vision for the scope of CT education. In this regard, CT education requires a certain form of motivation, encouragement and pedagogical support. One way to provide such support is to develop appropriate skills and dispositions. It should be noted that, as the narrative suggests, any skill can be developed independently and without linkage to other skills in the overall skill set. The overall goal of such education is to engage students in social interaction, both through the use of modern media and media-supported communication skills and directly in face-to-face interpersonal interaction. This is accomplished through the directed development of soft skills as well as universal competencies such as planning and advanced communication skills. The narrative introduces the concept of a highly connected world and implicitly introduces the concept of $\mathrm{CT}$ as a mediator between the various disciplines of the curriculum. The motivation is also to prepare students for life and careers in this technology-rich, highly connected world through the acquisition of universal skills and competences.

From a pedagogical perspective, CT education is positioned as supported from infancy onwards. It is argued that CT is partially a kind of an inherent competence and the educator's goal is to unlock this potential. Another claim is that CT education supports general learning as it is positioned as the foundation of multiple development domains. As an example, CT is positioned as an "umbrella" or "magic wand" approach to learning, cognition and language and literacy, which encompasses the teaching for almost all known developmental skills and competencies. It is argued that there is a need to add a layer of intentionality in supporting computational thinking. Another direction is the professional development of teachers and educating parents on the principles of CT education. 
Looking at the issue of educational equity from a critical perspective, the problem of engaging underrepresented groups is addressed by locating the public library as a unique extracurricular environment, positioned as a highly competent complement to formal and home education. Such "advanced" competencies of libraries include CT educational competencies aimed directly at learning as well as engaging families and communities in CT-related educational and extracurricular activities. The narrative provides concrete examples of educational and developmental programs for children of different ages.

\subsection{Uncovering CT from the Social Semiotic Perspectives}

The resource focuses on engaging families in early development activities. Libraries and staff are positioned as professionals in early literacy and a holistic approach to early development. The motivation is that today's evolving digital realm requires new and specific approaches to education, and CT may serve as an appropriate solution. The resource consists of texts, visual (pictures), video and statements for interactive feedback. Focus groups are librarians targeting professional development, families and communities of interest.

The message is: promote libraries as institutions and particular libraries as providers of (a) innovative solutions for early development, (b) innovative educational solutions to prepare for future schooling, including new requirements such as STEM preparation and education for creativity, (c) solutions for community engagement, including underrepresented minorities and (d) solutions for the professional development of library professionals.

The resource tries to maximize the impact on individuals and community by: (a) expanding focus groups to include children of different ages, librarians, teachers, families, local communities and minorities; (b) promoting libraries as competent providers of non-formal and informal educational solutions and engaging families in early childhood development; (c) promoting libraries as advocates for the engagement of underrepresented communities in early education and development; (d) developing a range of multimodal educational and informational content and (e) promoting community networks through involvement into discussions and feedback.

The interests of the resource maker are as follows: (a) to expand the audience of library attendance by promoting innovative ways of early childhood development and education; (b) to promote certain libraries as leaders in innovation; (c) to promote certain leading professionals and $(\mathrm{d})$ to build the image of libraries as democratic institutions by declaring attempts to promote educational efforts of under-represented communities.

All of the above are linked to the following demands for the social change: (a) early childhood development and education engage children in modern competences such as digital literacy, creativity and STEM; (b) the active involvement of families in early childhood development and education aims to involve families more in their children's upbringing in order to develop a holistic personality with greater commitment to human and democratic values; (c) community involvement aims to develop family networking in child development in order to strengthen (local) communities by motivating information exchange, feedbacks and discussion and (d) promoting the involvement of under-represented communities, thereby increasing literacy and welfare.

The balance of power in social interaction aims to (a) promote professional development through the uptake of innovative development content and methodology; (b) emphasize the need for CT in early literacy as a prerequisite for continued success, as traditional literacy skills alone may be not sufficient to solve twenty-first-century challenges; (c) set the direction for online education, promoting $\mathrm{CT}$ as an important educational methodology that is especially relevant for engagement and motivation during COVID-19 and (d) promote the participation of libraries in the association as an institution responsible for the accumulation of knowledge and advanced professional competences.

The storyline of this narrative could be entitled "innovative approaches to early literacy". The relation to other plots can be found in the following dimensions: (a) CT for the continuous development of the whole child, starting at an early age and throughout 
primary and school education ("CT for school education"); (b) as a "starting point" for CT for STEM and professional development ("CT for STEM"); (c) as a practical example of innovative content for professional development for educators ("CT for professional development") and (d) as an innovative approach to digital competence acquisition for all, starting in early childhood ("CT as a competence for all"). Considering the wider landscape, the semiotic nature can be further represented by a kind of a "meta" semiotic triangle [26] revealing the latent concepts symbolized by CT (see Table 2). It is such variations that provide the terrain for the future development of the CT phenomenon.

Table 2. A landscape of semiotic triangles for CT conceptualization (elaborated by the authors).

\begin{tabular}{|c|c|c|}
\hline $\begin{array}{l}\text { Expression (Text, Other } \\
\text { Multimodal Resources) }\end{array}$ & Concept (Expression Symbolizes) & Referent (Virtual Artifact) \\
\hline $\begin{array}{l}\text { “Original" CT definitions-“"think like a } \\
\text { computer scientist", instructions, ready-made } \\
\text { descriptions, specific set of examples }\end{array}$ & Mental enhancer & $\mathrm{CT}$ as a cognitive artifact \\
\hline $\begin{array}{c}\text { CT Pamphlets, sales and advertising links } \\
\text { related to CT }\end{array}$ & Sales driver & $\begin{array}{l}\text { CT as a sales tool (of } \\
\text { educational materials) }\end{array}$ \\
\hline $\begin{array}{l}\text { Specific official provisions on CT education } \\
\text { policy, specific official provisions on CT training, } \\
\text { academic writings and "expertise" on } \\
\text { early/professional development, CT competence } \\
\text { framework, Education } 4.0 \text { framework }\end{array}$ & $\begin{array}{l}\text { Promoter of outstanding } \\
\text { professional competences }\end{array}$ & $\begin{array}{l}\mathrm{CT} \text { as a framework for } \\
\text { professional competences }\end{array}$ \\
\hline $\begin{array}{l}\text { Specific learning resources (text, videos, play } \\
\text { sets, descriptions of practical activities) }\end{array}$ & $\begin{array}{l}\text { Developer of outstanding } \\
\text { "public" competences }\end{array}$ & $\begin{array}{l}\mathrm{CT} \text { as a framework for } \\
\text { digital competences }\end{array}$ \\
\hline $\begin{array}{l}\text { Names of institutions and institution contacts, } \\
\text { links to associations, links to affiliated CT } \\
\text { "experts", links to institution resources }\end{array}$ & $\begin{array}{l}\text { Promoter of outstanding } \\
\text { affiliated organizations }\end{array}$ & $\mathrm{CT}$ as an institutional marketing tool \\
\hline
\end{tabular}

\section{Findings and Discussion}

\subsection{On the Conceptualization of CT Design in Terms of Sociosemantics}

Considering $\mathrm{CT}$ as a complex semiotic resource, we could first focus on issues related to multimodality. This includes designs, hidden meanings, means and corresponding modes. At the same time, from the perspectives of social semiotics, it is "interested in how modes change as power shifts at the interpersonal, institutional and societal levels" [38]. For example, by observing the internal structure of a CT-related artifact such as a multimodal web resource, the human actor engages in interaction with a number of modes such as textual (rhetorical, explanatory/instructive, academic/professional, hypertext/links, educational), visual (graphic_pictures, diagrams, videos), bodily/gestures (play activities, physical outdoor activities), programming (software interfaces, coding activities) and virtual (networking, virtual activities). As can be seen from the presented case, the artifact designer provides a number of features enabling a focus on semiotics when studying it. Even if the primary aim is to position it as an informative resource in early development and education, it can in fact be seen in terms of multimodal (social) semiotics as a set of means for power relations and social interaction with a wide group of actors.

The traditional text mode is a distinctive feature of educational information transfer, as it is associated with a teacher-centered approach to knowledge transmission. The internet translates it into a hypertextual document including links to visual and other modes. How does this relate to CT? Firstly, CT can be seen as a political agency for a kind of political influence on family institutions in order to engage "unpaid" resources in a form of personal efforts in a "project" of public participation in activities designated as "twentyfirst-century competences". Typically, such competences are mystified into some abstract and vague concepts such as "essential media literacy skills", etc. It seems that abstract "socio-technical" slogans such as it is crucial for everyone to thrive as a twenty-first century 
citizen will not produce the expected response from the public. The observed solution is to move from a kind of political "entreaty" to a set of mandatory precepts, turning them into compulsory requirements for "successful" schooling.

The word "computational" provides a semantic bridge to a chain of meanings related to technology and politics: "digital", "technology", "qualification", "better job", " prosperity" and "better life". And, accordingly, the word "thinking" provides a semantic bridge to the chaining of meanings related to cognition, cognitive development and education: "understanding", "abilities", "development", "the whole child" and "creativity". These provide a conceptual shift from a textual-based educational and academic focus to a refined multimodal focus of political rhetoric. A kind of a contradiction is observed. It is "declared" as a kind of a solution for under-represented groups, since no comprehensive prerequisites are required for participation. At the same time, it is supported by a range of paid support materials and services, which a certain number of higher-income families can afford. From this perspective, CT transduces traditional forms related to politically neutral academic knowledge into a "subtler" form of power relations in the form of "specifically structured" compulsory activities provided by public institutions such as public libraries.

When analyzing the rhetoric of the resource creator, one can notice an unconscious attempt to shift the focus away from the use of the "pamphlet approach" (PA) [65]. In general, pamphlets and brochures are widely used in traditional marketing [66]. Despite the penetration of digital forms, the essence remains the same: an emphasis on depersonalization and mass rhetoric aimed at promoting and marketing the resource institution and a range of free and paid educational resources. This is usually based on the use of certain "marketing stamps" under the label of CT, e.g., literacy and learning for life begin with talking, reading, playing, singing, E writing together! Want to know more about supporting CT skills? It is worth noting that this approach is not limited to printed "tangible" information and can be expanded to virtual resources focused on providing "issue-specific information on a single piece of paper or website" [65]. A key concept describing this approach is the self-responsibility of community members for "reaching and following through outside services" [65]. However, unlike a highly systematized field such as medicine, education based on library involvement is potentially more personalized and tailored to personal contact between learners and educators. Despite this, PA dominates as a strategy in the design of CT resources, although the claim that it is effective is questionable. The main disadvantage, from our point of view, is that instead of looking for points of contact and interest directly with community members, the emphasis is on service provision, thus shifting from education of CT affordances and nurturing of semiotic competences to a centralized education focused on teachers and power relations.

While the formally stated intention is to provide information, in reality it is focused on establishing and maintaining power relationships, as discussed previously. There is a clear reference to the library as a provider of expertise in CT. The statement-Want to know more about supporting CT skills with children and teens? Contact the library-is supported by links to eight paid resources and other references to the provider of expertise in a two-page small format brochure (see Figure 2). Another example is designed in a similar style. Based on a number of formal definitions of CT, which actually have a blurred meaning for the public to whom the presented pamphlets are addressed, there are numerous links to external educational resources (see Figure 3). We counted thirteen references to external resources on one page. The same style is maintained in the design of CT's auxiliary web resources. They are based on a mixture of academic texts, "blurred" CT definitions and links to CT educational resources, links to promotional activities of "experts" positioned as innovative service providers and links to free and paid services. 


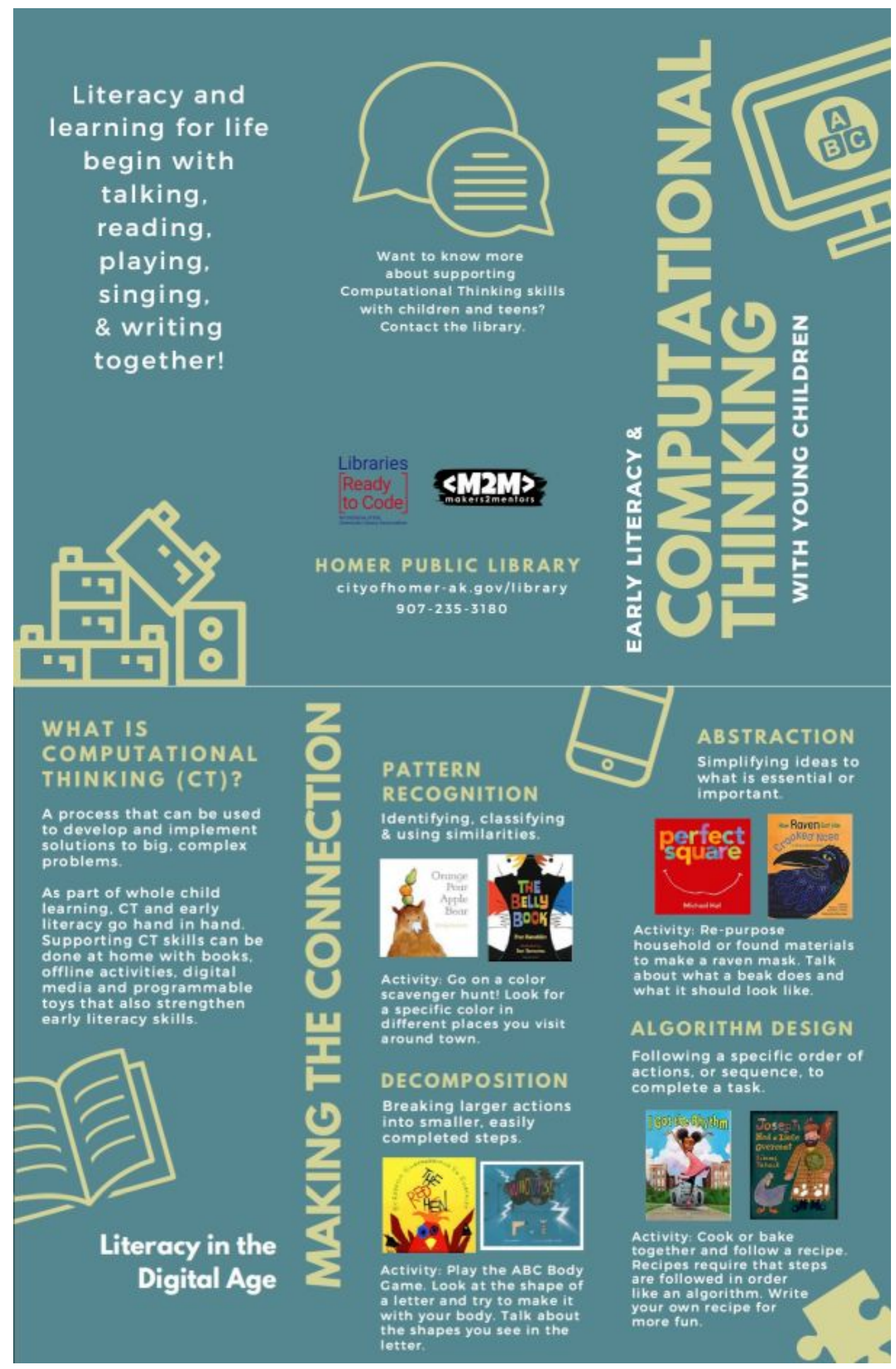

Figure 2. A CT pamphlet (retrieved with permission from https://www.ala.org/pla/initiatives/ familyengagement/compthinking, accessed on 10 December 2021). 


\section{PATTERN RECOGNITION \\ Identifying and classifying similarities. \\ For example, how your clothing is organized, the dishes are put away, or how a school day is organized. \\ Tit This}

Patterns at home: Ilow many different patterns can you makc with different objects at home? Sce if family members can guess your order.

Patterns outside: There are lots of patterns in nature and around the city. Where do you see patterns? Are those patterns repeated other places?

Titeritcy Iinks

Every English book is opened and read the same way. Tn Fnglish, the words are all printed and read from lelt to right. Understanding these patterns is called print awareness.

\section{Lcarn Moro}

liarmyard Bcat by Lindscy Craig Have You Scen My Dragon? by Steve Light I See a Pattern Here by Bruce Goldstone Monkey and Mc by Emily (iravett

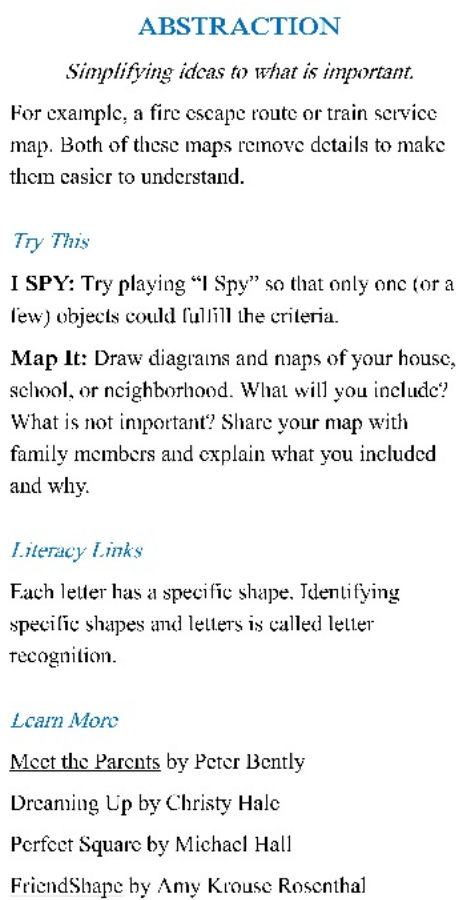

\section{ALGORITHM DESIGN}

The spociffe ordor of actions to comptetc a task:

For exainple, getting dressed or cooking a meal. When getting dressed, clothes have to be put on in a specific order. When cooking, some ingredients have to be mixed in a specific order.

Try This

How Do You Travel?: Talk about paths and routes while you travel. How many different ways to the buses and netro travel through and around the city? llow many different ways could you travel from your home to a location? Why do you pick specific rontes?

\section{Literacy Links}

Telling a story and sequencing an order ol events is called narrative skills. Stories and enditigs may change when the sequence of the story, or order of cvents, change. Guessing what may come next in a sequence is an important component of both algorithm design and narrative skills.

Learn Moro

Iell Me the Day Backwards by Albert Lamb

How To Read a Story by Katc Messner

Are We There Yet? by Dan Santat

\section{DECOMPOSITION}

Breaking latye tasks inio smaller acfivitics.

For exanuple, making a sandwich, brushing your teeth, or doing laundry.

\section{Thy this}

Child Chef: Make a pcanut butter and jelly sandwich with your child. Have them tell how to make it. liollow instructions precisely. lior cxample, where on the bread should the peanut butter go? IIow the bread should be cut or folded? See how detailed the instructions can be.

Break It Down: Fxplain tasks as you do them, Most of our activities are broken into smaller tasks.

Litcracy Link

Letlers and sounds are the building blocks of syllables and words. Breaking sentences into words and words into syllables is decomposition of languagc.

Learn More

Airport Book by Lisa Brown

Liveryone Can Learn to Ride a Bicycle by Chris Raschka

\section{WHAT IS COMPUTATIONAL THINKING?}

How do we lackle big, complex problems? How do we accomplish large tasks?

We break them into smaller, easily completed activities. We find pattems and repeat actions. We create and maintain routines.

We use the same skills with computers and coding, in other words: Computational Thinking skills.

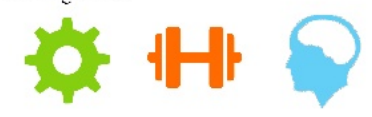

Have you continued these learning skills at home? I el us know by contacling your local DC: Public Library.

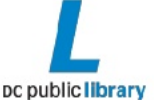

\section{Ready, Set, Think!}
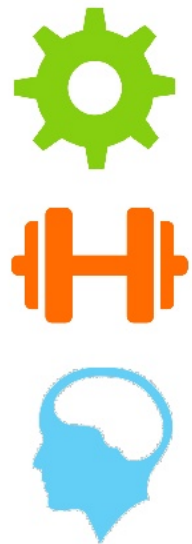

Unite early literacy and Computational Thinking concepts to gain early coding skills.

\section{$\langle$ libraries/ready to code $>$}

Figure 3. A CT pamphlet (retrieved with permission from https://www.ala.org/pla/initiatives/ familyengagement/compthinking, accessed on 10 December 2021).

\subsection{The Design of CT in Terms of Its Agentive Features}

When considering $\mathrm{CT}$ as a social phenomenon, the following question arises-how should its entities be designed? Such an entity is a multimodal resource, directed, as seen in the case study presented, at the interconnection of sociotechnical, political and promotional issues. Hence its presentational form as a combination of rhetorical strategies aimed at promoting political declarations, supporting educational techniques and marketing 
activities. At the same time, as can be seen, the institution of CT is in a period of maturation aimed at recognizing its semiotic nature and growing away from a "naïve" understanding of its role and context of application. As is natural for political institutions, it is underpinned by a kind of ideology of promoting "values", based on existing or newly created media and oriented towards some existing or prospective community at which rhetorical activity is directed (see Table 3), representing a kind of matrix of CT development trends in relation to uncovering its inherent critical scripting features.

Table 3. The CT "scripting" landscape (elaborated by the authors).

\begin{tabular}{|c|c|c|c|c|}
\hline \multirow{3}{*}{. } & \multicolumn{2}{|c|}{ CT in the development of its "scripting" landscape } & $\begin{array}{l}\text { Existing focus groups: } \\
\text { Schools, academics, community for } \\
\text { programming/coding education }\end{array}$ & $\begin{array}{l}\text { "Emerging" focus groups: } \\
\text { Families and associated } \\
\text { communities, minority and } \\
\text { under-represented groups, } \\
\text { educational policy makers, } \\
\text { industry, business and } \\
\text { education entrepreneurs }\end{array}$ \\
\hline & $\begin{array}{l}\text { "Emerging" media and } \\
\text { communicative tools: }\end{array}$ & $\begin{array}{l}\text { Narratives and social } \\
\text { networks, marketing and } \\
\text { promotional resources, } \\
\text { commercial and } \\
\text { sales resources }\end{array}$ & $\begin{array}{l}\text { "Updated" CT as a set of activities } \\
\text { to develop advanced competences: } \\
\text { CT for STEM, Makers movement, } \\
\text { CT-related contests, Visual } \\
\text { programming activities }\end{array}$ & $\begin{array}{l}\text { Towards the "new" rhetoric of CT } \\
\text { (CT as a must for thriving society): } \\
\text { early development and education, } \\
\text { family literacy, promotion of } \\
\text { democratic values }\end{array}$ \\
\hline & $\begin{array}{l}\text { Already presented media } \\
\text { and communicative tools: }\end{array}$ & $\begin{array}{l}\text { Academic papers and } \\
\text { popular journal articles, } \\
\text { informative web pages }\end{array}$ & $\begin{array}{l}\text { Promoting "classical" definitions } \\
\text { of CT: CT for } \\
\text { programming/coding and specific } \\
\text { competences related to CT }\end{array}$ & $\begin{array}{l}\text { "Expanding" CT definitions: CT for } \\
\text { all, CT for 21-st century competences }\end{array}$ \\
\hline
\end{tabular}

When considering $\mathrm{CT}$ from an unbiased phenomenological perspective, we observe a tendency to design virtual CT entities (e.g., virtual environments dedicated to $\mathrm{CT}$ ) by positioning CT as a (meta-) semiotic transducer of "mediated" knowledge into the first-hand knowledge and cultural meanings (explicit social dimension) into socio (-cultural) factors (implicit social dimension) (see Table 4), providing a kind of matrix of CT "development" trends in relation to its inherent transducing capabilities.

Table 4. CT trends as a semiotic transducer (elaborated by the authors).

\begin{tabular}{|c|c|c|c|}
\hline \multirow{4}{*}{ 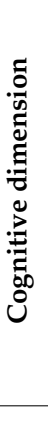 } & CT as a semiotic transducer & $\begin{array}{l}\text { Social environment: } \\
\text { communities, values, attitudes, } \\
\text { agency, networking }\end{array}$ & $\begin{array}{l}\text { Sociocultural environment: } \\
\text { traditions, ethnography, aesthetics, nature, } \\
\text { ecological perception }\end{array}$ \\
\hline & $\begin{array}{l}\text { First-hand knowledge: } \\
\text { knowledge gained through perception }\end{array}$ & $\begin{array}{l}\text { Emulation, bricolage, interpretation, } \\
\text { conceptual understanding: } \\
\text { informal education, master classes, "summer" } \\
\text { schools, developmental programs (libraries, } \\
\text { museums), workshops }\end{array}$ & $\begin{array}{l}\text { Semiotic competences, perception of CT } \\
\text { affordances: emerging educational } \\
\text { environments [67], social } \\
\text { entrepreneurship [68], digital } \\
\text { entrepreneurship [69], social work }\end{array}$ \\
\hline & $\begin{array}{l}\text { Mediated knowledge: } \\
\text { knowledge gained through interaction }\end{array}$ & $\begin{array}{l}\text { Traditional schooling, formal education, } \\
\text { compulsory curriculum }\end{array}$ & $\begin{array}{c}\text { Maker culture [70], professional networks: } \\
\text { maker places, contests, STEM } \\
\text { environments, webinars, internships }\end{array}$ \\
\hline & & Sociocultural dimension & \\
\hline
\end{tabular}

By examining CT from a critical perspective, the trend towards further development of its inherently sociogenic features can be considered. This can be represented by integrating aspects of educational methodology and educational policy. The trend is to use the inherent characteristics of CT to further strengthen power relations and promote political goals, seeing CT as a tool to promote "political" and "business" values. This opens the way to considering the development of CT as a specific "anthropogenic" and sociogenic mediator (see Table 5). 
Table 5. Steps towards unravelling CT as a sociogenic mediator (elaborated by the authors).

\begin{tabular}{|c|c|c|c|}
\hline \multirow{3}{*}{ 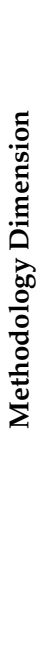 } & $\begin{array}{l}\text { CT in the development of its } \\
\text { sociogenic features }\end{array}$ & $\begin{array}{l}\text { Educational environment: formal (schools) } \\
\text { and semi-formal (libraries, after school } \\
\text { activities) education }\end{array}$ & $\begin{array}{l}\text { Political environment: formal instructions, } \\
\text { directions given, policies, political goals }\end{array}$ \\
\hline & $\begin{array}{l}\text { CT as an agentive means: } \\
\text { focusing on developing new and } \\
\text { maintaining the integrity of } \\
\text { existing power relations }\end{array}$ & $\begin{array}{l}\text { Positioning CT as a kind of "anthropogenic" } \\
\text { mediator: focusing on developing a set of a } \\
\text { mandatory competences ("thinking like a } \\
\text { computer scientist", advanced digital } \\
\text { competences, CT for all) for the } 21 \text {-st century } \\
\text { learner; focusing on development of specific, } \\
\text { e.g., "digital" competences }\end{array}$ & $\begin{array}{l}\text { Further revealing CT as a suicidogenic } \\
\text { mediator: focus on power relations; } \\
\text { positioning "responsible" institutions as } \\
\text { "experts" in innovative approaches in } \\
\text { education; instruction is aimed at introducing } \\
\text { a range of formally recognized, mandatory } \\
\text { activities; focus on educators and their } \\
\text { professional development }\end{array}$ \\
\hline & $\begin{array}{l}\text { CT as an aim: focusing on } \\
\text { "definitive" features of CT }\end{array}$ & $\begin{array}{l}\text { Positioning CT as an educational } \\
\text { aim-focusing on development of CT skills } \\
\text { and general competences: school as the } \\
\text { modern environment for CT education; family } \\
\text { as the responsible unit (transfers on-the-shelf } \\
\text { educational solutions to the child "as a } \\
\text { whole"); preparing for schooling; focus on } \\
\text { cognitive development }\end{array}$ & $\begin{array}{l}\text { Integrated approaches focused on establishing } \\
\text { (maintaining) power relations (mandatory } \\
\text { activity for): the underrepresented community } \\
\text { for social inclusion; the "modern" educator } \\
\text { ("digital" certification); "responsible" parents } \\
\text { (commercial resource kit for the } \\
\text { "computational thinker"); focus on social and } \\
\text { personal development }\end{array}$ \\
\hline
\end{tabular}

\subsection{Towards a "Semiotic" CT Curriculum}

The next aspect to be discussed relates to the notion of perceived $\mathrm{CT}$ affordances. This is a rather challenging question: is it possible to perceive CT affordances (if any), and how does this sound in practice? When we talk about affordances, we are usually referring to (tangible) objects. However, in the case of $\mathrm{CT}$, we are faced with a complex phenomenon based on cultural, social, technical and political discourses. In this case, the meaning of affordances is more complex and includes various interdisciplinary aspects (see, e.g., [71]). The perception of CT affordances enables the transition to a meta-level that explicitly highlights the socio-cultural aspects of the CT semiotic competences in the resources being designed. In this respect, for example, technical competences (e.g., mathematical or coding abilities to be developed) can be understood as a consequence (or subset) of the development of (extended) semiotic competences (see, for example, [34] for the meaning and discussion of "semiotic competences") mediated by the transductive nature of a virtual phenomenon such as CT. As a consequence, we can formulate the following recommendations for an activity to design an appropriate educational environment that considers the transformative nature of CT (in terms of affordances) and focuses on an extended teaching (training) program to develop CT in terms of semiotic competences. It can be based on existing infrastructure such as museums and libraries or on emerging infrastructure such as STEM centers or Maker networks and maker places, and should aim at further developing relevant educational activities and supportive infrastructure. This goes beyond traditional teacher-student relationships to include an extended environment based on engaged communities and socio-cultural initiatives.

As an illustration, the earlier presented examples of play activities can be examined. Manipulations or "actions" with "objects" or toys are positioned based on discrete parameters like, color, shape, size, function, etc. Another area of activities is bodily activities, which include dancing and singing, although it is positioned as a motivation-supported activity and is not directly related to pedagogical goals. Looking at these CT-related activities from a pedagogical point of view, the description states that the aim of education is the acquisition of CT skills. It is worth noting that there is an attempt to move from the explicitly declared "traditional" pedagogical skills related to CT to "new" skills such as those related to general CT "competences". Another point worth mentioning concerns the declaration of the purpose of cognitive development, describing its ultimate goal as growing a computational thinker. There is no clear definition of what a computational thinker is; however, there is an implicit definition of a computational thinker as someone with CT competences. At the same time, a linear model is declared; i.e., we can call a person 
with partial competences an emerging computational thinker. This illustrates that when considering CT as an end (as opposed to considering it as a means), the emphasis is placed on instructional design to create conditions and support for learner-centered activities aimed at building CT competences. One such approach is to integrate educational tools into educational activities aimed at CT.

On the contrary, when considering CT as a means, the design activity should focus on creating the conditions for the process of scaffolding the learner's semiotic competences, such as discovering the affordances mediated by CT. In this case, it is a matter of implicitly and explicitly stating the spectrum of affordances in order to develop an instructional design to scaffold the process of perception of the affordances in the learning process. The paradigm shift is from understanding to perception, from the separation of cultural and social to an integrated phenomenological one. Any activity must be directed towards the realization of (perceptive) affordances that the semiotic phenomenon represents. The meaning of "affordances" is controversial and needs some clarification. It is not equal to the meaning (even implicitly) of "possibilities". Affordances are "perceived possibilities" mediated by a role of the signifying phenomenon (in our case, CT is seen as a multimodal artifact). This conditions the shift to sociocultural dependence of "resources" as "an attempt to better engage with the direct perception of the human environment in all its messy cultural and social complexity" [37].

It is important to note that the described (perceived) affordances are "conceptual" features of the objects, phenomena and events being studied, so the task of the instructional designer is not to provide instructional support and materials for learning CT definitions and acquiring CT "competences", but rather to provide instructional support and materials for scaffolding the perception of CT affordances (as a semiotic resource) that it mediates. To summarize, the process of CT-empowered instructional design is based on the following considerations: (a) CT is seen as a referent (an artifact with multimodal-textual, visual, bodily, virtual, etc.--forms of its representation); (b) CT (as a semiotic phenomenon) serves as a mediator (a sign) enabling the perception of inherent affordances based on a (c) reference (considered as a concept, a hidden meaning opposite to the "referent" — the real object to which the sign points [37]) and (d) providing a learning path through the perception of CT affordances to the cognitive development of the learner (via instructional scaffolding).

\subsection{Additional Issues}

The following questions should be discussed in relation to future studies: What is the (agentive) attitude to the concept "perception of reality" [48] and how does this affect aspects of educational design? This is important as it reveals the inherent issues of (a) the agency of meaning makers and (b) highlights aspects inherent in the semiotics realm. CT as an entity claims to be multimodal and virtual, making the underlying semiotic realm arguably transcendental [72] and immersed in the implicit cognitive intentions of the agentic meaning-maker. Such transcendental issues may be responsible for shaping the contingent realm of possible worlds of the transcendental future [58]. Moreover, we could continue the process of unravelling the ways and means of transferring "from empirical reality towards the transcendences", [58] uncovering the metaphoric nature of the semiotic realm of the $\mathrm{CT}$ phenomenon.

The limitations of the study include the following issues. First, a focus on a single case can possibly narrow the discursive landscape and prospects for generalizations. To overcome this limitation, we focused on the set of interlinked resources accessible through the main webpage. This yielded an extensive, unstructured set of multimodal resources related to the topic under study. Further, we focused on a single-country case, which could provide country-specific insights based on its historical and cultural perspectives related to the topic under study. This limitation can be planned to be overcome through further comparative research by including other countries in the data set.

The development of CT educational methodology in the narrative described is based on a positivist perception of reality as being grounded in some invariants and universals 
that shape the phenomenon under study. The author's aim is to uncover the structure of a set of such universals with the intention of developing an innovative educational methodology, for example, to support the whole child. This assumes the common good of computational intelligence, seeing it as a resource that reveals the ontological structure of the immanent semiotic realm. At the same time, however, this assumes methodological universals that allow educators to challenge themselves to think differently and to develop innovative methodological approaches oriented to universal values in early childhood development. This provides an example of the controversy between the positivist and pragmatist [73] realms in education, providing a practical example of the concept of metaphorical "clash" [48] as a driver of the conceptual and phenomenological development of CT. At the same time, it gives us an example of applying semiotic means in development towards transcendences by "packaging" explicitly accessible discursive universalities of CT, such as decomposition, pattern recognition, abstraction and algorithmic design, into its transcendental counterpart in the form of the described cognitive challenges for educational staff.

\section{Conclusions}

The study focuses on trends in CT as a multimodal phenomenon. The approach is to reflect analytically on the "hidden" meanings or implicit aspirations that see CT as a vehicle for social transformations and the strengthening and maintenance of power relations. The presented case study provides a clear example of the phenomenon of CT and the design and utilization of its entities in early development and education practice. At the same time, the focus of the study is on the dynamics of CT and is linked to cultural and social dimensions that position CT as a means for socio-cultural transformations. It is the semiotic focus that allows us to highlight the multimodal features of CT and emphasize the impact on the social and power relations it mediates.

\subsection{CT and Institutional Conceptualization}

The following research questions were formulated: what are the main aspects of CT in terms of (R1) its institutional conceptualization and (R2) its development trends? When answering the research questions, the presented case study was analyzed in terms of social semiotics. The case study positions CT and its corresponding educational activities as a prerequisite for success in schooling and further professional achievements. Despite the fact that the resource is extensively supported by multimedia, making it more acceptable to families and the general public, it includes some academic-style texts in order to highlight the level of competence of the resource creator. Regarding conceptualization, a kind of "meta" semiotic triangle was identified, defining a number of emerging CT conceptualizations, such as CT as a "mental enhancer", "sales driver", "promoter of outstanding professional competences", "developer of outstanding 'public' competences" and "promoter of outstanding affiliated organizations". Although the resource is positioned as educational, it is actually aimed to strengthen the position of the resource maker (the association of public institutions-public libraries) in maintaining and establishing power relationships with subordinate institutions as well as with local communities and families involved in early childhood education and early development. In essence, this is aimed at marketing purposes as fulfilling the responsibilities and obligations of resource makers to sate funded institutions. CT as a semiotic resource enables, through its complex structure and multimodal nature, the conceptualization of signifying content focused on social change through systematic engagement with the concept of family literacy. The identification of this "hidden" semiotic agenda provides insights into further power-building and policy-oriented action mediated by CT.

\subsection{CT and Development Trends}

Regarding development trends, the study presents CT phenomenological trends in the form of three trend matrixes. The first focuses on unravelling the "scripting" landscape of $\mathrm{CT}$. We can conclude that the trend of CT development is towards unraveling its inherent 
scripting features on the basis of emerging media and focus groups that CT rhetoric is aimed at. Starting from "classical" media such as academic papers, journal articles and web pages as "embedding" media to introduce "traditional" CT rhetoric based on CT definitions related to coding and programming style competences, it evolves into a broad set of narratives and networked media for "updated" CT as a network-based set of activities for "advanced" competences. Regarding focus groups, there is a clear development trend from schools and academia to the involvement of associated and under-represented communities and stakeholders by positioning CT as a policy tool.

The next trend we can conclude is the development of CT in the direction of further revealing its inherent nature as a semiotic transducer. In the cognitive dimension, starting from a focus on "embedded" socially interactive knowledge gained in a form of traditional schooling, there is a tendency to move towards first-hand knowledge gained through non-formal education and early development activities. In the other, sociocultural dimension, we consider a development trend moving from interaction with an explicit social environment embedded into formal or non-formal educational settings to a socio-cultural environment based on close interaction and socio-cultural integration and supported by advanced semiotic competences mediated by CT.

Another trend we observed relates to the revelation of the inherent features of $\mathrm{CT}$, such as a sociogenic mediator. Starting from a "traditional" view of CT as a set of competences and a goal of educational activities embedded into traditional and advanced educational environments, such as school or family education, it evolves into a set of mandatory competences explicitly presented and promoted by the CT curriculum. CT contributes to the acquisition of specific knowledge and defined competences and reveals its role as a kind of "anthropogenic" mediator. Educational methodology is being transformed from viewing CT as an educational goal, focusing on its definitions, to utilizing CT as a means to develop the learner's digital competences. In the political dimension, there is a tendency to reveal the sociogenic role of CT in the form of establishing and maintaining power relations and promoting certain political values through the introduction of mandatory requirements and a set of formally recognized competences.

\subsection{Further Work and Concluding Remarks}

By further analyzing CT in terms of semiotics, we can notice an inherent conceptual controversy, which can be seen as an internal driving force supported by the multimodality of CT representational entities and its phenomenological development (see, for example, $[39,48]$ for illustrations of controversies and clashes as driving forces for the development of various phenomena). The process of semiosis, namely "the active, ontological process of the discovery of meaning in and as existence-as-process" [74] (in relation to CT) should be further developed as future research. This refers to both to practical and methodological issues. For example, what is the conceptual representation for the dimensions of CT semiosis? And from the pragmatist stance: what are the possibilities for the further development of the CT phenomenon in terms of manifesting its semiotics affordances?

This study continues the authors' efforts to present a new vision of CT education, focusing on a conceptual understanding of the sociotechnical transformations it mediates. It can be considered as the next step toward a more comprehensive semiotic understanding of CT as it applies to early childhood education and development, as well as to the continuation of the authors' earlier work on the subject. Whereas the authors' previous work on the subject [75] focuses on the "whole" landscape of CT, this research, on the contrary, following the tradition of semiotics, focuses on a kind of a "micro level", providing an examination of one particular case and extending it with a kind of subsequent generalization as related to CT and its conceptual and phenomenological understanding.

As mentioned earlier, this study also attempts to unravel the power networks and "hidden" political rhetoric set against the background of the educational context of CT. Overall, the problems raised in this study can be generalized to a broader context of educational politics and issues of power related to, perhaps unconsciously, hidden attempts to establish 
a power network based on a kind of outstanding expertise requiring modern knowledge. As a result, one is confronted with the emergence of a post-industrial technocracy [76], leading to a division of society into a technocratic elite and a subordinated public. The consequence of this is a conceptual shift in the positioning of what used to be considered purely technical as a kind of means to reestablish power relations and, as a consequence, to increase political influence. This study provides a practical example of such an emerging issue, presents a "cross-section" of its transformative practice and identifies directions for its further conceptual development.

Author Contributions: Conceptualization, V.D. (Vladimiras Dolgopolovas) and V.D. (Valentina Dagiene); methodology and formal analysis, V.D. (Vladimiras Dolgopolovas); investigation, V.D. (Vladimiras Dolgopolovas); resources, V.D. (Vladimiras Dolgopolovas); writing-original draft preparation, V.D. (Vladimiras Dolgopolovas) and V.D. (Valentina Dagiene); writing-review and editing, V.D. (Valentina Dagiene) and V.D. (Vladimiras Dolgopolovas); supervision, V.D. (Valentina Dagiene); project administration, V.D. (Valentina Dagiene). All authors have read and agreed to the published version of the manuscript.

Funding: This research received no external funding.

Institutional Review Board Statement: Not applicable.

Informed Consent Statement: Not applicable.

Data Availability Statement: Original data available on request. They are not archived in any repository.

Acknowledgments: The authors acknowledge Nicklas Anttu for his thoughtful proofreading of this paper.

Conflicts of Interest: The authors declare no conflict of interest.

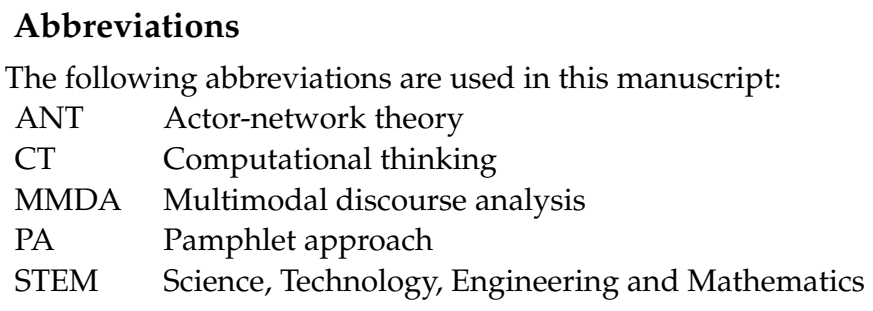

\section{References}

1. Jacob, S.R.; Warschauer, M. Computational Thinking and Literacy. J. Comput. Sci. Integr. 2018, 1, 1-19. [CrossRef]

2. Prins, E.; Clymer, C.; Kaiper-Marquez, A.; Willson, B. Family Literacy. In The Handbook of Adult and Continuing Education; Stylus Publishing, LLC: Sterling, VA, USA, 2020; pp. 205-213.

3. Khine, M.S. Computational Thinking in the Stem Disciplines: Foundations and Research Highlights; Springer: Cham, Switzerland, 2018.

4. Pears, A.; Barendsen, E.; Dagienè, V.; Dolgopolovas, V.; Jasute, E. Holistic STEAM Education Through Computational Thinking: A Perspective on Training Future Teachers. In Lecture Notes in Computer Science; Springer: Cham, Switzerland, 2019; Volume 11913, pp. 41-52. [CrossRef]

5. Dolgopolovas, V.; Dagienè, V. Computational Thinking: Enhancing STEAM and Engineering Education, from Theory to Practice. Comput. Appl. Eng. Educ. 2021, 29, 5-11. [CrossRef]

6. Dagienè, V.; Sentence, S. It's Computational Thinking! Bebras Tasks in the Curriculum. In Informatics in Schools: Improvement of Informatics Knowledge and Perception, Proceedings of the International Conference on Informatics in Schools: Situation, Evolution, and Perspectives, Münster, Germany, 13-15 October 2016; Lecture Notes in Computer Science; Springer: Singapore, 2016; Volume 9973, pp. 28-39. [CrossRef]

7. Dougherty, D. The Maker Movement. Innov. Technol. Gov. Glob. 2012, 7, 11-14. [CrossRef]

8. Strasser, B.J.; Baudry, J.; Mahr, D.; Sanchez, G.; Tancoigne, E. “Citizen Science”? Rethinking Science and Public Participation. Sci. Technol. Stud. 2019, 32, 52-76. [CrossRef]

9. Palts, T.; Pedaste, M. A Model for Developing Computational Thinking Skills. Informatics Educ. 2020, 19, 113-128. [CrossRef]

10. Denning, P.J.; Tedre, M. Computational Thinking; MIT Press: Cambridge, MA, USA, 2019.

11. Lodi, M.; Martini, S. Computational Thinking, Between Papert and Wing. Sci. Educ. 2021, 30, 883-908. [CrossRef]

12. Denscombe, M. The Good Research Guide: For Small-Scale Social Research Projects, 4th ed.; Open University Press: Maidenhead, UK, 2014.

13. Rogers, M.; Pfaff, T.; Hamilton, J.; Erkan, A. Using Sustainability Themes and Multidisciplinary Approaches to Enhance STEM Education. Int. J. Sustain. High. Educ. 2015, 16, 523-536. [CrossRef] 
14. Klink, T.; Sanger, M.; Olley, R.; Pakes, A.; Edil, T.; Klinzing, S. Early Introduction of STEM Through Sustainable Engineering. In Sustainable Environment and Infrastructure; Lecture Notes in Civil Engineering; Springer: Cham, Switzerland, 2021; Volume 90, pp. 13-20. [CrossRef]

15. Hinz, O.; Eckert, J.; Skiera, B. Drivers of the Long Tail Phenomenon: An Empirical Analysis. J. Manag. Inf. Syst. 2011, 27, 43-70. [CrossRef]

16. Freeman, R.; McMahon, C.; Godfrey, P. Design of an Integrated Assessment of Re-Distributed Manufacturing for the Sustainable, Resilient City. In Sustainable Design and Manufacturing 2016, Proceedings of the International Conference on Sustainable Design and Manufacturing, Heraklion, Greece, 4-6 April 2016; Smart Innovation, Systems and Technologies; Springer: Cham, Switzerland, 2016; Volume 52, pp. 601-612. [CrossRef]

17. Millard, J.; Sorivelle, M.N.; Katsikis, O.K.; Unterfrauner, E.; Voigt, C. The Maker Movement in Europe: Empirical and Theoretical Insights into Sustainability. In Proceedings of the EPiC Series in Computing, Toronto, ON, Canada, 14-18 May 2018; Volume 52, pp. 227-242. [CrossRef]

18. Millard, J.; Sorivelle, M.N.; Deljanin, S.; Unterfrauner, E.; Voigt, C. Is the Maker Movement Contributing to Sustainability? Sustainability 2018, 10, 2212. [CrossRef]

19. Easterbrook, S. From Computational Thinking to Systems Thinking: A Conceptual Toolkit for Sustainability Computing. In Proceedings of the ICT for Sustainability 2014, ICT4S 2014, Stockholm, Sweden, 24-27 August 2014; pp. 235-244. [CrossRef]

20. Norman, D.A.; Stappers, P.J. DesignX: Complex Sociotechnical Systems. She Ji J. Des. Econ. Innov. 2015, 1, 83-106. [CrossRef]

21. Sang, W.; Simpson, A. The Maker Movement: A Global Movement for Educational Change. Int. J. Sci. Math. Educ. 2019, 17, 65-83. [CrossRef]

22. Rode, J.A.; Marshall, A.; Weibert, A.; Aal, K.; Von Rekowski, T.; El Mimouni, H.; Sharma, A.; Jobs, J.; Schleeter, A.; Booker, J. From Computational Thinking to Computational Making. In Proceedings of the 2015 ACM International Joint Conference on Pervasive and Ubiquitous Computing, Osaka, Japan, 7-11 September 2015; pp. 401-402. [CrossRef]

23. Ezeamuzie, N.O.; Leung, J.S.C. Computational Thinking Through an Empirical Lens: A Systematic Review of Literature. J. Educ. Comput. Res. 2021, 1-31. [CrossRef]

24. Jones, P. Designing for X! The Challenge of Complex Socio-X Systems. She Ji J. Des. Econ. Innov. 2015, 1, 101-104.

25. Ma, J. A Review of the DesignX Discourse: Knowledge Diffusion and Integration Across Disciplines. In Cross-Cultural Design. Methods, Tools and User Experience, Proceedings of the International Conference on Human-Computer Interaction, Orlando, FL, USA, 26-31 July 2019; Lecture Notes in Computer Science; Springer: Cham, Switzerland, 2019; Volume 11576, pp. 57-78. [CrossRef]

26. Atkin, A. Peirce's Theory of Signs. In The Stanford Encyclopedia of Philosophy; Zalta, E.N., Ed.; Metaphysics Research Lab, Stanford University: Stanford, CA, USA, 2013. Available online: https://plato.stanford.edu/archives/sum2013/entries/peirce-semiotics/ (accessed on 5 February 2022).

27. Norman, D.A. Cognitive artifacts. In Designing Interaction: Psychology at the Human-Computer Interface; Millar, J., Long, J., Eds.; Cambridge University Press: Cambridge, UK, 1991; Volume 1, pp. 17-38.

28. Norman, D.A. Design Principles for Cognitive Artifacts. Res. Eng. Des. 1992, 4, 43-50. [CrossRef]

29. Yaneva, A. Making the Social Hold: Towards an Actor-Network Theory of Design. Des. Cult. 2009, 1, 273-288. [CrossRef]

30. Simon, H.A. The Science of Design: Creating the Artificial. Des. Issues 1988, 4, 67-82. [CrossRef]

31. Matthews, A. Design as a Discipline for Postdigital Learning and Teaching: Bricolage and Actor-Network Theory. Postdigital Sci. Educ. 2019, 1, 413-426. [CrossRef]

32. Papert, S.; Harel, I. Situating Constructionism. Constructionism 1991, 36, 1-12.

33. Norman, D. The Design of Everyday Things; Revised \& Expanded Edition; Basic Books: New York, NY, USA, 2013.

34. Campbell, C.; Olteanu, A.; Kull, K. Learning and Knowing as Semiosis: Extending the Conceptual Apparatus of Semiotics. Sign Syst. Stud. 2019, 47, 352-381. [CrossRef]

35. Gibson, J.J. The Ecological Approach to Visual Perception; Psychology Press: Hove, UK, 2014.

36. Sassower, R. Digital Exposure: Postmodern Postcapitalism; Palgrave Macmillan: London, UK, 2013.

37. Windsor, W.L. An Ecological Approach to Semiotics. J. Theory Soc. Behav. 2004, 34, 179-198. [CrossRef]

38. Jewitt, C.; Bezemer, J.; O'Halloran, K. Introducing Multimodality; Routledge: London, UK, 2016.

39. Perrotta, C.; Selwyn, N. Deep Learning Goes to School: Toward a Relational Understanding of AI in Education. Learn. Media Technol. 2020, 45, 251-269. [CrossRef]

40. Macedonia, M. Embodied Learning: Why at School the Mind Needs the Body. Front. Psychol. 2019, 10, 1-8. [CrossRef] [PubMed]

41. Ginsborg, H. Kant's Aesthetics and Teleology. In Stanford Encyclopedia of Philosophy; Zalta, E.N., Ed.; Metaphysics Research Lab, Stanford University: Stanford, CA, USA, 2005; pp. 1-29. Available online: https://plato.stanford.edu/archives/win2019/entries/ kant-aesthetics / (accessed on 5 February 2022).

42. Wheeler, W. 1. The Lightest Burden: The Aesthetic Abductions of Biosemiotics. In Handbook of Ecocriticism and Cultural Ecology; De Gruyter: Berlin, Germany, 2016; pp. 19-44. [CrossRef]

43. Rabinow, P.; Rose, N. The Essential Foucault: Selections from the Essential Works of Foucault, 1954-1984; New Press: New York, NY, USA, 2003.

44. Dator, J. What Futures Studies Is, and Is Not. In Jim Dator: A Noticer in Time; Anticipation Science; Springer: Cham, Switzerland, 2019; Volume 5, pp. 3-5. [CrossRef]

45. Latour, B. Reassembling the Social—An Introduction to ANT; Oxford University Press: Oxford, UK, 2005. 
46. Van Leeuwen, T. Introducing Social Semiotics; Routledge: New York, NY, USA, 2004.

47. Dolan, T.E. Framing Indeterminacy: Dialectical Analysis and Futures Studies. World Futur. Rev. 2018, 10, 83-94. [CrossRef]

48. Carbonell, J.; Sánchez-Esguevillas, A.; Carro, B. The Role of Metaphors in the Development of Technologies. The Case of the Artificial Intelligence. Futures 2016, 84, 145-153. [CrossRef]

49. Spangsberg, T.H.; Brynskov, M. The Nature of Computational Thinking in Computing Education. Int. J. Inf. Educ. Technol. 2018, 8, 742-747. [CrossRef]

50. McLaren, P. Rethinking the Dialectic: A Social Semiotic Perspective for Educators. Educ. Theory 1991, 41, 23-46. [CrossRef]

51. Hui, Y. Recursivity and Contingency; Rowman \& Littlefield: London, UK, 2019.

52. Knöbl, W. Contingency. In Critical Terms in Futures Studies; Palgrave Macmillan: Cham, Switzerland, 2019; pp. 53-59. [CrossRef]

53. Frank, U. Theories in the Light of Contingency and Change: Possible Future Worlds and Well-Grounded Hope as a Supplement to Truth. In Proceedings of the Annual Hawaii International Conference on System Sciences, Puako, HI, USA, 4-7 January 2017; Volume 2017, pp. 5727-5736. [CrossRef]

54. Miller, R. Futures Literacy-Embracing Complexity and Using the Future. Ethos 2011, 10, 23-28. Available online: https: / / www.csc.gov.sg/articles / opinion-futures-literacy-embracing-complexity-and-using-the-future (accessed on 1 January 2022).

55. Anderson, K.T.; Holloway, J. Discourse Analysis as Theory, Method, and Epistemology in Studies of Education Policy. J. Educ. Policy 2020, 35, 188-221. [CrossRef]

56. Hesse-Biber, S.N. Mixed Methods Research: Merging Theory with Practice. In Qualitative Social Work; Guilford Press: New York, NY, USA, 2012; Volume 11, pp. 220-225. [CrossRef]

57. Kress, G. Multimodal discourse analysis. In The Routledge Handbook of Discourse Analysis; Routledge: Abingdon, UK, 2013; pp. 35-50. [CrossRef]

58. Tarasti, E. Metaphors, Semiotics and Futures Studies. Futures 2016, 84, 120-123. [CrossRef]

59. Inayatullah, S.; Izgarjan, A.; Kuusi, O.; Minkkinen, M. Metaphors in Futures Research. Futures 2016, 84, 109-114. [CrossRef]

60. Ryan, M.L. Virtuality. In Critical Terms in Futures Studies; Palgrave Macmillan: Cham, Switzerland, 2019; pp. 335-341. [CrossRef]

61. Haynes, P. How We Became Posthuman: Virtual Bodies in Cybernetics, Literature and Informatics by N. Katherine Hayles. Body Soc. 2001, 7, 105-108. [CrossRef]

62. Public Library Association. Computational Thinking. Available online: https://www.ala.org/pla/initiatives/familyengagement/ compthinking (accessed on 3 January 2022).

63. Moustakas, C. Heuristic Research: Design, Methodology, and Applications; Sage Publications: Thousand Oaks, CA, USA, 1990.

64. Interaction Desing Foundation Heuristics and Heuristic Evaluation. Available online: https://www.interaction-design.org/ literature/book/the-glossary-of-human-computer-interaction/heuristics-and-heuristic-evaluation (accessed on 4 January 2022).

65. Zellmer, L. A Closer Look at the Pamphlet Approach. Minnesota Med. 2018, 31-33. Available online: https://www. mnmed.org/getattachment/news-and-publications/mn-medicine-magazine/Past-Issues/Past-Issues-2018/March-April-20 18/Commentary-ZELLMER-180304.pdf.aspx?lang=en-US (accessed on 6 February 2022).

66. Lawrence, S.; Deshmukh, S.; Navajivan, E. A Comparative Study of Digital Marketing vs. Traditional Marketing. IIBM's J. Manag. Res. 2018, 3, 112-121. [CrossRef]

67. Browder, R.E.; Aldrich, H.E.; Bradley, S.W. The Emergence of the Maker Movement: Implications for Entrepreneurship Research. J. Bus. Ventur. 2019, 34, 459-476. [CrossRef]

68. B Bayik, M.F. Social Innovation and Social Entrepreneurship. In Creating Business Value and Competitive Advantage With Social Entrepreneurship; IGI Global: Hershey, PA, USA, 2019; pp. 92-114. [CrossRef]

69. Sahut, J.M.; Iandoli, L.; Teulon, F. The Age of Digital Entrepreneurship. Small Bus. Econ. 2021, 56, 1159-1169. [CrossRef]

70. Mike, S.; Mike, S. Maker culture. In Practical Pedagogy; Routledge: New York, NY, USA, 2019. [CrossRef]

71. Sun, Y.; Suthers, D.D. Cultural Affordances and Social Media. In Proceedings of the Annual Hawaii International Conference on System Sciences, Honolulu, HI, USA, 5-8 January 2021; Volume 2020, pp. 3017-3026. [CrossRef]

72. Tarasti, E. What Is Existential Semiotics? From Theory to Application. Chinese Semiot. Stud. 2009, 1, 25-39. [CrossRef]

73. David Plowright, A. Charles Sanders Peirce: Pragmatism and Education; Springer: Cham, Switzerland, 2016.

74. Brenner, J.E.; Igamberdiev, A.U. Philosophy in Reality: Scientific Discovery and Logical Recovery. Philosophies 2019, 4, 22. [CrossRef]

75. Dolgopolovas, V.; Dagiene, V. On the Future of Computational Thinking Education: Moving beyond the Digital Agenda, a Discourse Analysis Perspective. Sustainability 2021, 13, 13848. [CrossRef]

76. Esmark, A. The New Technocracy; Policy Press: Bristol, UK, 2020. 